\title{
Genetic testing for exercise prescription and injury prevention: AIS-Athlome consortium-FIMS joint statement
}

\author{
Nicole Vlahovich ${ }^{1}$ David C. Hughes
Nobert Bachl ${ }^{1,6}$, Lyn R.
From 34th FIMS World Sports Medicine Congress \\ Ljubljana, Slovenia. $29^{\text {th }}$ September $-2^{\text {nd }}$ October 2016
}

\begin{abstract}
Background: There has been considerable growth in basic knowledge and understanding of how genes are influencing response to exercise training and predisposition to injuries and chronic diseases. On the basis of this knowledge, clinical genetic tests may in the future allow the personalisation and optimisation of physical activity, thus providing an avenue for increased efficiency of exercise prescription for health and disease.

Results: This review provides an overview of the current status of genetic testing for the purposes of exercise prescription and injury prevention. As such there are a variety of potential uses for genetic testing, including identification of risks associated with participation in sport and understanding individual response to particular types of exercise. However, there are many challenges remaining before genetic testing has evidence-based practical applications; including adoption of international standards for genomics research, as well as resistance against the agendas driven by direct-to-consumer genetic testing companies. Here we propose a way forward to develop an evidence-based approach to support genetic testing for exercise prescription and injury prevention.
\end{abstract}

Conclusion: Based on current knowledge, there is no current clinical application for genetic testing in the area of exercise prescription and injury prevention, however the necessary steps are outlined for the development of evidence-based clinical applications involving genetic testing.

\section{Background}

Physical inactivity accounts for approximately $6 \%$ of the worldwide burden of disease and globally, around $23 \%$ of adults aged 18 years and over did not meet physical activity guidelines in 2010 [1]. Physical inactivity increases the risk of developing a range of conditions including hypertension, coronary heart disease, stroke, diabetes, breast and colon cancer; while physical activity is a key determinant of energy expenditure, and fundamental to energy balance and weight control [1]. Engaging in physical activity on a regular basis (e.g.,

\footnotetext{
* Correspondence: Nir.Eynon@vu.edu.au

${ }^{7}$ Institute of Sport, Exercise and Active Living (ISEAL), College of Sport and Exercise Science, Victoria University, PO Box 14428, Melbourne, VIC 8001, Australia

Full list of author information is available at the end of the article
}

exercise training) is therefore crucial for increasing cardiorespiratory fitness and decreasing the risk for chronic diseases. Physical activity levels and the response to similar exercise training vary considerably, with some people being 'low/medium responders' (with limited improvements following exercise training), while others respond well or very well ('high responders') [2]. This variable response appears to be influenced by both environmental (e.g. training status, nutrition, social economic status) and genetic factors.

While there have been some advances in knowledge and understanding of how genes are influencing the response to exercise training and predisposition to injuries and chronic diseases, the development of genetic tests which allow the personalisation and optimisation of physical activity remains elusive [3]. In the future, such 
tests may provide an avenue for increased efficiency of exercise prescription and injury prevention. Additionally, there are a range of genetic conditions that may impede an individual's participation in exercise, with the most severe of these leading to an increased risk of sudden cardiac death $[4,5]$. In particular, genes associated with cardiomyopathies may be of interest to sports medicine physicians [5]. Discovering genes that are associated with the predisposition of the severest of common sports injuries has become a particular focus of research interest.

Minimising time loss from injury has been correlated with athletic success for both teams and individuals $[6,7]$. Additionally, sports injuries in recreational athletes have significant public health impact and consequences for future participation in sport and recreational activities [8]. Comprehensive injury surveillance is performed by many professional sporting bodies to examine the impact of particular injuries. The international bodies such as the International Olympic Committee (IOC) and the Fédération Internationale de Football Association (FIFA) systematically survey injuries in their major events [9-12]. For example, analysis of the London Olympic Games found that $11 \%$ of athletes reported an injury during the Games [12]. Prevention of injury in the sports arena is a high priority for athletes, coaches, high performance staff and medical personnel. Consequently, there has been significant research in the area of genetic variation and its impact on susceptibility to exercise-related injuries, with a particular focus on tendon and ligament injuries [13]. Much of this research is aimed at determining an individual's susceptibility to, and/or risk of acquiring a sport injury and implementing preventative strategies.

The rapid development of genetic and genomic techniques has led to an increase in interest in the genetics of physical activity and sport. The Athlome Project Consortium was established in 2015 to collectively study the limited genotype and phenotype data available in elite athletes, as well as focusing on adaptation to exercise training and exercise-related musculoskeletal injuries [14]. The ultimate goal of this consortium is to inform personalised training and injury prevention, as well as informing doping detection utilising collaborative and rigorous research. Often studies within the field of exercise/injury genomics are limited by cohort sizes and other methodological concerns. The Athlome consortium has recently advocated an approach to overcome the main gaps in this research field [14], and to serve as a collective guiding reference in the identification of reliable genetic tests for exercise training and sports injuries. This review provides a statement on the state of play in genetic testing for the purposes of exercise prescription and injury prevention.

\section{Potential uses of genetic testing for exercise and health \\ Identifying those who are at increased risk (or resilient) to musculoskeletal injury}

Participation in sport or exercise training can lead to acute and chronic musculoskeletal injuries. For athletes, time lost from training and competition due to injury has a profoundly negative impact on performance. Additionally, when a member of the public who is engaged in exercise training acquires an injury this can lead to a lack of motivation towards, or fear of returning to training [15]. Several factors, both intrinsic and extrinsic, are reported to predispose an individual to musculoskeletal injury, including demographic factors (e.g., sex, age, weight, and height), anatomical factors (e.g., leg length discrepancy, malalignment and decreased flexibility), and environmental conditions (e.g., training patterns, technique flaws and equipment) [16-19]. Genetic variations also play a role in the risk profile for musculoskeletal injury [13].

Identification of gene variations that may lead to an increased or decreased risk of sport/exercise injury has been studied for a range of conditions including ligament [20-23], tendon [22, 24-27], muscle [28, 29], and bone injuries [30, 31]. Primarily this has been done using the hypothesis-driven, candidate gene approach, where a case-control cohort is examined for genetic variation in genes of interest and the occurrence of musculoskeletal injuries, focusing on genes involved in the extracellular matrix and apoptosis pathways (e.g., [13]). To date there has been only one genome-wide association study (GWAS) published in the area of sports injury, which did not identify any significant gene variations contributing to Achilles tendon or ACL injury [32]. The sample sizes of the candidate gene studies have been quite small (typically between 100 and 200 cases) [33]. In contrast, GWAS have utilised tens to hundreds of thousands of individuals to identify genetic variants in migraine and Alzheimer's disease [34, 35]. It has been acknowledged that further investigation with appropriately sized cohorts is required to replicate and correctly interpret the association of identified polymorphisms with specific injuries [33]. Such studies should also be repeated in other populations, including non-Caucasian populations [26]. Importantly, gene-discovery studies should be accompanied by functional studies that would demonstrate, in either animal or human models, how newly identified gene variations could cause molecular/cellular changes leading to increased/decreased susceptibility to an injury.

There is future potential to use genetic screening in assessing risk of musculoskeletal injuries, providing an avenue to modify training, conditioning programs and physical therapy intervention in order to prevent 
injuries. The current level of evidence however does not support the clinical use of genetic screening. Further research is required to gain a deeper understanding of the range of gene variants that contribute to risk of injury and the effectiveness of personalised training regimens in reducing injury incidence when compared to usual training.

\section{Identifying high/low responders to specific training protocols in healthy and diseased populations}

Specific training protocols assist athletes, or exercise participants, in achieving fitness goals. Tailoring exercise programs to fit the specific needs of athletes and/or the general population may provide an efficient mechanism for rapid development of aerobic fitness and strength. From the response to exercise training literature, it has become clear that there is considerable individual variability in the response to similar exercise training [36]. The implications are that some individuals are 'low responders' (improving their fitness only slightly following a specific exercise training) while others respond well or very well ('high responders'). Response to training also seems to depend on the type and length of the exercise training protocol. For example, intense intermittent exercise, or interval training, has gained popularity in the last few years and is a powerful stimulus to induce many of the physiological adaptations typically associated with traditional, moderate-intensity continuous training [37]. However, not everyone responds similarly to this type of training, and it would appear that genetic variants play an important role in this variable response [2]. Uncovering the genes behind the individual response to exercise training therefore has exciting implications for "personal medicine" and the development of individualised exercise training and health programs. This development could have important health and economic ramifications by ensuring that specific types of exercise interventions are prioritised to those most likely to attain the greatest benefit.

Several types of chronic diseases, including cancer, have been shown to benefit from generalised physical activity, such as walking, or exercise training [38-42]. Examples of the application of different training types have shown that some chronic conditions are better suited to a particular type of training. Studies have shown that resistance training can improve cognitive function in patients with mild cognitive impairment, and can increase muscle strength and fat-free mass in frail elderly patients with sarcopenia $[43,44]$. Other studies have shown potential benefits to using either endurance or resistance training in chronic obstructive pulmonary disease, or that exercise and generalised physical activity is beneficial to those undergoing cancer treatment $[45,46]$. The application of genomic techniques to develop individual exercise prescription based on the type of disease and the patient's predicted response to exercise would assist in targeting treatment; so-called personalised medicine. While there is a great deal of research being undertaken to identify genetic predictors of response or non-response to specific exercise regimes, there are currently no valid genetic tests that can be clinically applied for this purpose.

\section{Identifying those who may have uncommon disorders and be at specific risk in sport}

Some genetic disorders do confer a significant health risk for individuals undertaking strenuous activity. Sudden cardiac death is the leading medical cause of death in athletes, with variable incidence rate in athlete subgroups, with the highest risk being reported in male African-American/black athletes and basketball players [47]. Several gene variants have been shown to be associated with cardiac electrophysiology, arrhythmias, and sudden cardiac death, however very few of these studies have been replicated and functional implications of the genes are not always clear [4]. There is therefore a pressing need to conduct research that could enable the risk of sudden cardiac death for each individual to be established and determine if the characteristics of a particular sport increases that risk [48]. Athletes with diagnosed heart conditions, such as hypertrophic cardiomyopathy, may be advised against participation in competitive sports and discouraged from intense physical activity, dependent on the severity of their condition [49].

Marfan syndrome is an inherited connective tissue disorder associated with ocular, musculoskeletal and cardiovascular manifestations, characterised by a tall and slender build and disproportionately long limbs, posing potential lethal threat during high-intensity exercise [50]. Marfan syndrome has an incidence of 4-20/ 100,000 depending on the population studied and diagnostic criteria used [51]. Marfan syndrome results most commonly from mutations in the fibrillin-1 gene on chromosome 15, which encodes for the glycoprotein fibrillin [52]. Where a family history, symptom history, physical examination or diagnostic investigations (slit lamp ocular examination, echocardiogram) raise suspicion of Marfan syndrome, molecular studies of the fibrillin gene may be useful in clarifying the diagnosis. Marfan syndrome is one condition that disproportionately affects athletes in sports where height provides a distinct advantage due to the athletic phenotype caused by genetic mutations. Sudden death by aortic aneurysm and dissections represent the most serious clinical manifestation of this disease, and as such, sporting organisations where a tall slender build with long limbs is advantageous (such as volleyball and basketball) may see the need to mitigate this risk by using screening of athletes. 
Conducting a clinical evaluation should always be the first step before performing a genetic test. Genetic testing is especially indicated in the following scenarios; positive family history of inherited heart disease (e.g., cardiomyopathies, channelopathies, aortopathies) or suspicion of that type of disease (e.g., syncope episodes, arrhythmias, cardiac arrest, sudden death); or when the athlete's phenotype strongly indicates the presence of an inherited disease (Marfan syndrome) [49]. Sporting organisations wishing to conduct genetic investigations into conditions that may lead to increased risk of sudden cardiac death should engage a medical practitioner to ensure that appropriate clinical examination and counselling takes place prior to conducting genetic testing.

\section{Challenges for genetic testing in sport and exercise medicine \\ Cohort size}

One of the major limitations in the field of exercise/injury genomics is the relatively low sample size of subjects and/or the general population participating in exercise training studies. Major collaborative effort is required for the field to progess, and enhance our understanding of the genes that influence the response to exercise and predisposition to injury. Improving cohort numbers in current biobanks would pave the way for genome-wide testing. To date, the analysis of single variant candidate genes (often poorly justified) using lowthroughput techniques has yielded conflicting findings and inconsistent results. Current GWAS and WholeGenome Sequencing (WGS) technology means that millions of gene variants are analyzed per individual [53]. A recent study utilised 375,000 individuals to identify 38 loci related to susceptibility of migraine [35]. A similar style of genome-wide approach, designed with sufficient power could identify specific regions or variants that contribute to increased/decreased susceptibility to injuries and the response to exercise training.

As a result of the rapid advances in the development and uptake of high-throughput DNA-sequencing methods, progress is now being made in understanding the genetic basis of rare, and also some of the common diseases [54]. The first attempt to utilise a GWAS approach for athletic performance was recently undertaken by an international consortium (GAMES) [55]. This GWAS involved two cohorts of elite endurance athletes and controls (GENATHLETE and Japanese endurance runners), from which a panel of 45 promising markers was identified. These markers were tested for replication in seven additional cohorts of endurance athletes and controls: from Australia, Ethiopia, Japan, Kenya, Poland, Russia and Spain. This first of a kind study was based on a total of 1520 endurance athletes (835 who took part in endurance events in World Championships and/or
Olympic Games) and 2760 controls. Although this investigation did not identify a panel of genomic variants common to these elite endurance athlete groups, some of the suggestive leads identified warrant further investigation in expanded comparisons of world-class endurance athletes and sedentary controls and in tightly controlled exercise training studies [55].

In a recent, more successful effort to discover the genes associated with muscle strength, Willems et al. [56] examined the genetic loci associated with hand grip strength, which is a marker of muscular fitness and frailty, with lower hand grip strength associated with lower quality of life. Results were obtained from a combined sample of 195,180 individuals, initially utilising a UK DNA Biobank, with follow up analysis in independent samples of elite sprinters. The significant cohort size lead to identification of 16 loci associated with grip strength $\left(P<5 \times 10^{-8}\right)$ in combined analyses. A number of these loci contain genes implicated in structure and function of skeletal muscle fibres (ACTG1), neuronal maintenance and signal transduction (PEX14, TGFA, SYT1), or monogenic syndromes with involvement of psychomotor impairment (PEX14, LRPPRC and KANSL1). Importantly, this recent discovery provides new biological insight into the mechanistic underpinnings of muscle strength.

\section{Cohort homogeneity}

Another limitation common to the field of exercise/injury genomics is the cohort homogeneity. The majority of studies in sport and exercise genetics have been conducted using Caucasian/European subjects. While the homogeneity of the cohort assists in discovery of potential gene variants of significance, this poses a problem for the application of genetic tests to the broader community. Although we predict that the development of assessment tools will benefit from individual genomic information, not all of these applications may be extrapolated from the Caucasian cohorts to other populations. Encouragingly, there have been some recent attempts to study the genome of Asian (i.e., Chinese, Japanese, Taiwanese) and South American (i.e., Brazilian) athletes [57-59]. This trend is increasingly growing with the use of collaborative approaches and data sharing between international research centers.

An additional consideration in cohort homogeneity is the gene-by-sex interactions. Exercise genomic studies primarily utilise mixed cohorts of males and females, and account for sex differences as a covariate in their statistical analyses. For example, compelling findings of sex-dependent genetic effects on disease have been reported in type II diabetes [60] and autism spectrum disorders [61], which further complicates 
the issue of pooling together females and males into one cohort.

\section{Growth of DTC companies promoting non-evidence based testing}

There has been a rapid expansion of direct-to-consumer (DTC) genetic testing services, with those services being provided to members of the public on a commercial basis without any involvement of a medical practitioner [62]. A range of companies offer DTC genetic testing, purporting to examine how one's genes contribute to their athletic prowess. DTC companies commonly offer advice in terms of trainability or personalised training programs, predisposition to athletic success in power/endurance sports, and advice relating to weight loss management [62], despite the lack of evidence to support such advice. This type of DTC marketing targets athletes, parents, coaches and people from the general population seeking an athletic 'edge', and altered response to exercise training for success in sporting performance.

There are numerous problems inherent with the provision of advice based on the current repertoire of DTC genetic tests. In 2006, the United States Government Accountability Office (GAO) investigated companies selling DTC genetic tests and testified that these companies made medically unproven disease predictions [63]. For example, samples sent from the one individual to different DTC genetic companies resulted in inconsistent reporting between companies, including conflicting risk predictions for a range of diseases [63]. A systematic review of DTC genetic tests concluded that it is unacceptable that online companies offer genetic testing lacking scientific evidence and having no proven clinical utility, and make misleading marketing claims [64]. Recent research also suggests that DTC genetic testing companies massively exaggerate the predictive powers of their tests by distorting scientific evidence to support unfounded claims and in doing so have eroded the faith in the science behind genetic testing [65]. In response to this situation, a number of countries have instigated legislation to ensure that genetic testing cannot be carried out without the involvement of a medical practitioner, while there is no such legislated protection for consumers in certain other countries [66-68]. However, the DTC tests that draw conclusions about sporting performance do not provide health advice to the consumer and, therefore, may not meet the criteria to be regulated under current legislation.

A joint FIMS-Athlome Consensus Statement in 2015 warned against the use of DTC tests in athletes, stating that the current level of genetic knowledge is being misrepresented implicitly for commercial purposes and concluding that there is no place for DTC testing for predicting sports performance and talent identification [62].
Recently, the Australian Institute of Sport (AIS) has also developed a position statement to address the implications of recent advances in the field of genetics and the ramifications for the health and well-being of athletes [69].

\section{Potential ethical dilemmas}

Numerous ethical dilemmas exist in relation to genetic testing, for purposes other than medicine. Genomic testing raises a number of important issues for those prescribing the test, including the complexity of informed consent, sample and data storage, return of results, testing involving children, and privacy and confidentiality [70]. The AIS detailed their position in relation to the ethical dilemmas facing genetic and genomic testing of athletes [69]. In brief, genomic and genetic testing for non-medical purposes must be well thought out, with clear and transparent planning for all aspects of information management outlined prior to the commencement of testing. The right of refusal for non-participation must be respected and there should be no discrimination against athletes based on their participation in testing or the results attained from a genetic or genomic test. A clear process, involving genetic counselling, should be outlined for dealing with unintentional discoveries that may confer a health risk to the participant.

Additionally, there is a capability gap in the genetic literacy of many current medical practitioners and the readiness of the medical industry to provide the relevant infrastructure to use genomics as part of usual care. Several experts have stated that the challenges for integration of clinical genomics into mainstream medical care include the education of providers and patients, the provisions of appropriate regulatory framework and the accrual of sufficient evidence to draw relevant conclusions [71]. Genetic information may be difficult to interpret for a sports medicine provider who has not had additional training in this area [72]. The risk conferred by gene variants differ significantly from the risk conferred from genetic tests for Mendelian or single-gene disorders. Genetic discoveries are often difficult to translate into clinical practice. There are complexities in determining which gene variants are associated with increased risk, which have no impact on exposure to risk and whether an increase in disease risk is clinically meaningful (e.g., from $15 \%$ to $16 \%$ ). For this reason, it is important that practitioners understand the impact of the testing prescribed, and are able to provide counselling to the individual on the risks of genetic testing or to have access to a genetic counsellor should the need arise $[71,72]$.

\section{Unsafe use of technology e.g., CRISPR-Cas9 for genetic manipulation}

The ease of accessing gene-editing techniques, such as the CRISPR-Cas 9 technique, may make this inexpensive, cut-and-paste type of gene-editing an attractive 
option for athletes wishing to use genetic performance enhancement. Sports performance is an area where current genetic knowledge already suggests somatic modifications that could provide performance enhancement [73]. Despite ease of access to this technology, gene-editing remains imprecise and should only be conducted by highly skilled specialists for specific medical indications and when approved by the appropriate authorities. The danger is that athletes and coaches are seen as potential early adopters of illicit performance enhancing technologies [74]. There is no role for geneediting for the purposes of performance enhancement and all genetic manipulations are banned under the World Anti-Doping Agency Code [75]. Nevertheless, research efforts involving state-of-the-art 'omics' methods such as transcriptomics, proteomics and metabolomics are being intensified, also by FIMS and members of the Athlome Project Consortium, in order to identify robust molecular signatures of doping that have particular relevance in detecting gene-editing manipulations.

\section{The way forward}

International collaborations and utilising high throughput sequencing technologies to identify genes that contribute to exercise response

The challenge continues to be that it is difficult for one organisation to gather sufficiently high numbers of samples to provide meaningful analysis with clinical predictive value. The solution is large-scale multi-centre collaborations to drive research in this area and to ensure appropriate cohort size and homogeneity.

The cost of these rapidly improving sequencing techniques has been significantly reduced in the last decade. While the first human genome took $\$ 2.7$ billion and almost 15 years to complete, the cost to sequence a genome has now been drastically reduced to close to $\$ 1000$ ('The $\$ 1000$ genome' era) [76]. The $\$ 1000$ genome refers to an era of predictive and personalised medicine during which the cost of fully sequencing an individual's genome is roughly USD $\$ 1000$. This already allows scientists to sequence hundreds of thousands of genomes and will certainly have implications in advancing the field of exercise/injury genomics.

Two symposia were held in 2015 and 2016; the first in Greece and the second, in Slovenia, in partnership with the International Federation of Sports Medicine (FIMS), to review the main findings in exercise genetics and genomics and to explore promising trends and possibilities [14]. Among the participants, many were involved in ongoing collaborative studies (e.g., GAMES, Gene SMART, GENESIS and POWERGENE). A consensus emerged among participants that it would be advantageous to bring together all current studies and those recently launched into one new large collaborative initiative, which was subsequently named the Athlome Project Consortium. A website for the new consortium has been developed (www.athlomeconsortium.org), and clear goals have been established with steps to achieve these [14]. The intention is not for the Athlome Project Consortium to provide exclusivity but rather to serve as a model for sustainable and ethical research in sport and exercise medicine. In the few years since the launch of the Athlome project consortium, there has been much progress, with particular highlight the stimulation of multiple international collaborative research initiatives and joint research publications such as the present series published in BMC Genomics. The two previously mentioned GWAS investigations that involved members and cohorts associated with the Athlome consortium $[55,56]$ are further examples of encouraging outcomes to date. The main obstacle for further sustainable growth of the Athlome project consortium has been its operation during a time of sustained global research grant 'famine' for expensive large-scale collaborative research initiatives in sport and exercise medicine. More consortia and large multi-centre research initiatives are expected to follow such as the GenotypeTissue Expression (GTEx) program (https://commonfund.nih.gov/gtex) recently launched by the NIH-USA and envisaged to provide valuable insights into the mechanisms of gene regulation by studying human gene expression and regulation in multiple tissues from healthy individuals; exploring disease-related perturbations in a variety of human diseases; and examining sexual dimorphisms in gene expression and regulation in multiple tissues.

\section{The usefulness of genetic testing in changing behavior}

There are challenges that health and exercise professionals, along with coaches from high performance athletic programs, may face that relate to compliance with exercise or preventative health programs built on genetic analysis. Recent studies have demonstrated that directto-consumer cancer risk estimates do not appear to affect health-related behaviors positively or negatively [77]. Despite being informed of their relative risk for a variety of cancers, most adults did not significantly change their diet, exercise, advanced care planning, or cancer screening behaviors [78]. One must ask; if adults are unlikely to change their health behavior in relation to a serious medical condition such as cancer, will personalised genomics be relevant in the exercise and sportsinjury space? Understanding of the various behaviors that relate to sports injury risk and exercise prescription is needed before the relevance of genetic testing in these fields can be uniformly applied. Many studies have investigated the compliance or adherence to health-related exercise programs and interventions in relation to sports injury prevention [79-82]. In relation to elite sport, a study involving top UEFA football elite clubs 
demonstrated that athletes' adherence to the injury prevention programs remain varied, although coach compliance was rated as 'high' [83]. This implies that attitudes towards intervention programs reflect the beliefs of the individual and not necessarily that of coaches or support staff. Collard et al. recommend that a behavioral approach and 'intervention mapping' is required when defining a sports-injury prevention program to increase the risk of adherence [84]. A systematic approach is required in planning health promotion strategies, under which injury prevention and exercise prescription may be considered [85]. In addition, any possibility of introducing genetic testing in the elite sport scenario would need to be accompanied by education to athletes and support staff in order to improve genetic literacy.

\section{Conclusions}

Having considered the current level of scientific knowledge, the opinion of the stakeholders of this joint statement is that the predictive value of such tests is too low to warrant clinical application. The risks associated with this type of testing, including privacy issues, unintended genetic discoveries and erroneous advice based on poor evidence, should be mitigated with understanding of the test limitations, management of the data produced, and avoidance of advice that is not supported by scientific evidence. Additionally, organisations interested in the concept of genetic testing for exercise prescription and injury prevention should develop and clearly articulate the ethical framework within which that organisation is prepared to conduct genetic testing and research. Genetic testing for the purposes of exercise prescription and injury prevention may in the future be a legitimate and valid use of genetic information contributing health benefits to individuals with a wide range of athletic ability and injury predisposition. In order for genetic testing to become a useful component of medical practice, intensive international collaboration will be required.

\section{Acknowledgements}

Not applicable.

\section{Funding}

Publication of this manuscript was supported by the Australian Institute of Sport, and Victoria University, Australia.

Availability of data and materials

Not applicable.

\section{About this supplement}

This article has been published as part of BMC Genomics Volume 18 Supplement 8, 2017: Proceedings of the 34th FIMS World Sports Medicine Congress. The full contents of the supplement are available online at https:// bmcgenomics.biomedcentral.com/articles/supplements/volume-18-supplement-8.

\section{Authors' contributions}

Conceived the study: NE, YP. Performed review: NV. Wrote the manuscript: $\mathrm{NV}, \mathrm{DH}, \mathrm{NE}$. All authors have read and approved the final manuscript.
Ethics approval and consent to participate

Not applicable.

\section{Consent for publication}

Not applicable.

Competing interests

The authors declare that they have no competing interests.

\section{Publisher's Note}

Springer Nature remains neutral with regard to jurisdictional claims in published maps and institutional affiliations.

\section{Author details}

${ }^{1}$ Australian Institute of Sport (AIS), Australian Sports Commission, Canberra, Australia. ${ }^{2}$ Genomics Research Centre, Institute of Health and Biomedical Innovation (IHBI), Queensland University of Technology, Brisbane, Australia. ${ }^{3}$ Reference Collaborating Centre of Sports Medicine for Anti-Doping Research, University of Brighton, Eastbourne, UK. "Department of Movement Human and Health Sciences University of Rome "Foro Italico", Rome, Italy ${ }^{5}$ International Federation of Sports Medicine (FIMS), Lausanne, Switzerland. ${ }^{6}$ Department of Sports and Exercise Physiology, Centre for Sports Science and University Sports of the University of Vienna, Vienna, Austria. 'Institute of Sport, Exercise and Active Living (ISEAL), College of Sport and Exercise Science, Victoria University, PO Box 14428, Melbourne, VIC 8001, Australia. ${ }^{8}$ University of Canberra Research Institute for Sport and Exercise (UCRISE), University of Canberra, Canberra, Australia.

Published: 14 November 2017

\section{References}

1. Physical Activity Fact Sheet [http://www.who.int/mediacentre/factsheets/ fs385/en/] Accessed 20 May 2017.

2. Bishop DJ, Granata C, Eynon N. Can we optimise the exercise training prescription to maximise improvements in mitochondria function and content? Biochimica et Biophysica Acta (BBA)-General Subjects. 2014; 1840(4):1266-75.

3. Bouchard C, Antunes-Correa LM, Ashley EA, Franklin N, Hwang PM, Mattsson CM, Negrao CE, Phillips SA, Sarzynski MA, Wang P-Y. personalized preventive medicine: genetics and the response to regular exercise in preventive interventions. Prog Cardiovasc Dis. 2015;57(4):337-46.

4. Deo R, Albert CM. Epidemiology and genetics of sudden cardiac death. Circulation. 2012:125(4):620-37.

5. Stein R, Trujillo JP, Silveira ADd, Lamounier Júnior A, Iglesias LM: Genetic Evaluation, Familial Screening and Exercise. Arquivos Brasileiros de Cardiologia 2017(AHEAD):0-0.

6. Eirale C, Tol J, Faroog A, Smiley F, Chalabi H. Low injury rate strongly correlates with team success in Qatari professional football. Br J Sports Med. 2013;47(12):807-8.

7. Raysmith BP, Drew MK. Performance success or failure is influenced by weeks lost to injury and illness in elite Australian track and field athletes: a 5-year prospective study. J Sci Med Sport. 2016;19(10):778-83.

8. Finch C, Cassell E. The public health impact of injury during sport and active recreation. J Sci Med Sport. 2006;9(6):490-7.

9. Junge A, Dvorák J. Football injuries during the 2014 FIFA world cup. Br J Sports Med. 2015;49(9):599-602.

10. Junge A, Dvorak J: Injury surveillance in the world football tournaments 1998-2012. British journal of sports medicine 2013:bjsports-2013-092205.

11. Steffen K, Engebretsen L. Injury and illness surveillance among Olympic athletes: summary of the 2010 winter, and the 2008 and 2012 summer Olympic Games. In: Sports Injuries and Prevention. Springer; 2015. p. 39-50.

12. Engebretsen $L$, Soligard T, Steffen $K$, Alonso JM, Aubry M, Budgett R, Dvorak J, Jegathesan M, Meeuwisse WH, Mountjoy M. Sports injuries and illnesses during the London summer Olympic Games 2012. Br J Sports Med. 2013; 47(7):407-14

13. Collins M, September AV, Posthumus M. Biological variation in musculoskeletal injuries: current knowledge, future research and practical implications. Br J Sports Med. 2015;49(23):1497-503.

14. Pitsiladis YP, Tanaka M, Eynon N, Bouchard C, North KN, Williams AG, Collins M, Moran CN, Britton SL, Fuku N. Athlome project consortium: a concerted 
effort to discover genomic and other "omic" markers of athletic performance. Physiol Genomics. 2016;48(3):183-90.

15. Ardern CL, Österberg A, Tagesson S, Gauffin H, Webster KE, Kvist J. The impact of psychological readiness to return to sport and recreational activities after anterior cruciate ligament reconstruction. Br J Sports Med. 2014;48(22):1613-9.

16. Oestergaard Nielsen R, Buist I, Srensen H, Lind M, Rasmussen S. Training errors and running related injuries: a systematic review. International journal of sports physical therapy. 2012;7(1)

17. Taunton JE, Ryan MB, Clement D, McKenzie DC, Lloyd-Smith D, Zumbo B. A retrospective case-control analysis of 2002 running injuries. Br J Sports Med. 2002;36(2):95-101.

18. Snoeker BA, Bakker EW, Kegel CA, Lucas C. Risk factors for meniscal tears: a systematic review including meta-analysis. J Orthop Sports Phys Ther. 2013; 43(6):352-67.

19. Weiss $K$, Whatman C. Biomechanics associated with patellofemoral pain and ACL injuries in sports. Sports Med. 2015;45(9):1325-37.

20. John R, Dhillon MS, Sharma S, Prabhakar S, Bhandari M. Is there a genetic predisposition to anterior cruciate ligament tear? A systematic review. Am J Sports Med. 2016;44(12):3262-9.

21. Mannion S, Mtintsilana A, Posthumus M, van der Merwe W, Hobbs H, Collins M, September AV: Genes encoding proteoglycans are associated with the risk of anterior cruciate ligament ruptures. British journal of sports medicine 2014:bjsports-2013-093201.

22. Gibbon A, Hobbs H, Van der Merwe W, Raleigh SM, Cook J, Handley C, Posthumus M, Collins M, September A. The MMP3 gene in musculoskeletal soft tissue injury risk profiling: a study in two independent sample groups. J Sports Sci. 2017;35(7):655-62.

23. Posthumus M, September AV, Keegan M, O'Cuinneagain D, Van der Merwe W, Schwellnus MP, Collins M. Genetic risk factors for anterior cruciate ligament ruptures: COL1A1 gene variant. Br J Sports Med. 2009;43(5):352-6.

24. Mokone G, Schwellnus M, Noakes T, Collins M. The COL5A1 gene and Achilles tendon pathology. Scand J Med Sci Sports. 2006;16(1):19-26.

25. Posthumus M, Collins M, Cook J, Handley CJ, Ribbans WJ, Smith RK, Schwellnus MP, Raleigh SM. Components of the transforming growth factor- $\beta$ family and the pathogenesis of human Achilles tendon pathology_a genetic association study. Rheumatology. 2010;49(11):2090-7.

26. Raleigh SM, Collins M. Gene variants that predispose to Achilles tendon injuries: an update on recent advances. Achilles tendon. 2012:25-40.

27. September AV, Cook J, Handley CJ, van der Merwe L, Schwellnus MP, Collins M. Variants within the COL5A1 gene are associated with Achilles tendinopathy in two populations. Br J Sports Med. 2009;43(5):357-65.

28. da Rocha Motta G, Amaral MV, Rezende E, Pitta R. Dos Santos Vieira TC, Duarte MEL, Vieira AR, Casado PL: evidence of genetic variations associated with rotator cuff disease. J Shoulder Elb Surg. 2014;23(2):227-35.

29. Teerlink CC, Cannon-Albright LA, Tashjian RZ. Significant association of fullthickness rotator cuff tears and estrogen-related receptor- $\beta$ (ESRRB). J Shoulder Elb Surg. 2015;24(2):e31-5.

30. Varley I, Hughes DC, Greeves JP, Stellingwerff T, Ranson C, Fraser WD, Sale C. RANK/RANKL/OPG pathway: genetic associations with stress fracture period prevalence in elite athletes. Bone. 2015:71:131-6.

31. Levinger I, Yan X, Bishop D, Houweling PJ, Papadimitriou I, Munson F, Byrnes E, Vicari D, Brennan-Speranza TC, Eynon N. The influence of a-actinin-3 deficiency on bone remodelling markers in young men. Bone. 2017;98:26-30.

32. Kim SK, Roos TR, Roos AK, Kleimeyer JP, Ahmed MA, Goodlin GT, Fredericson M, loannidis JP, Avins AL, Dragoo JL. Genome-wide association screens for Achilles tendon and ACL tears and tendinopathy. PLOS One. 2017;12(3):e0170422.

33. September A, Posthumus M, Collins M. Application of genomics in the prevention, treatment and management of Achilles tendinopathy and anterior cruciate ligament ruptures. Recent patents on DNA \& gene sequences. 2012;6(3):216-23.

34. Lambert J-C, Ibrahim-Verbaas CA, Harold D, Naj AC, Sims R, Bellenguez C, Jun G, DeStefano AL, Bis JC, Beecham GW. Meta-analysis of 74,046 individuals identifies 11 new susceptibility loci for Alzheimer's disease. Nat Genet. 2013;45(12):1452-8.

35. Gormley P, Anttila V, Winsvold BS, Palta P, Esko T, Pers TH, Farh K-H, Cuenca-Leon E, Muona M, Furlotte NA. Meta-analysis of 375,000 individuals identifies 38 susceptibility loci for migraine. Nat Genet. 2016:48(8):856.
36. Bouchard C, Rankinen T: Individual differences in response to regular physical activity. Medicine and science in sports and exercise 2001, 33(6 Suppl):S446-451; discussion S452-443.

37. Gibala MJ, Hawley JA. Sprinting toward fitness. Cell Metab. 2017;25(5):988-90.

38. Bauman A, Merom D, Bull FC, Buchner DM, Singh MAF. Updating the evidence for physical activity: summative reviews of the epidemiological evidence, prevalence, and interventions to promote "active aging". The Gerontologist. 2016;56(Suppl 2):S268-80.

39. Dennett AM, Peiris CL, Shields N, Prendergast LA, Taylor NF. Moderateintensity exercise reduces fatigue and improves mobility in cancer survivors: a systematic review and meta-regression. J Phys. 2016;62(2):68-82.

40. Marzetti E, Calvani R, Tosato M, Cesari M, Di Bari M, Cherubini A, Broccatelli M, Savera G, D'Elia M, Pahor M. Physical activity and exercise as countermeasures to physical frailty and sarcopenia. Aging Clin Exp Res. 2017:1-8.

41. Van Haren IE, Timmerman H, Potting CM, Blijlevens NM, Staal JB, Nijhuis-van der Sanden MW. Physical exercise for patients undergoing hematopoietic stem cell transplantation: systematic review and meta-analyses of randomized controlled trials. Phys Ther. 2013;93(4):514.

42. Hearing C, Chang W, Szuhany K, Deckersbach T, Nierenberg A, Sylvia LG. Physical exercise for treatment of mood disorders: a critical review. Current Behavioral Neuroscience Reports. 2016;3(4):350-9.

43. Singh MAF, Gates N, Saigal N, Wilson GC, Meiklejohn J, Brodaty H, Wen W, Singh N, Baune BT, Suo C. The study of mental and resistance training (SMART) study - resistance training and/or cognitive training in mild cognitive impairment: a randomized, double-blind, double-sham controlled trial. J Am Med Dir Assoc. 2014;15(12):873-80.

44. Binder EF, Yarasheski KE, Steger-May K, Sinacore DR, Brown M, Schechtman $\mathrm{KB}$, Holloszy JO. Effects of progressive resistance training on body composition in frail older adults: results of a randomized, controlled trial. J Gerontol Ser A Biol Med Sci. 2005;60(11):1425-31.

45. lepsen UW, Jørgensen KJ, Ringbaek T, Hansen H, Skrubbeltrang C, Lange P. A systematic review of resistance training versus endurance training in COPD. Journal of cardiopulmonary rehabilitation and prevention. 2015;35(3): 163-72.

46. Juvet L, Thune I, Elvsaas $1 \varnothing$, Fors E, Lundgren S, Bertheussen $G$, Leivseth $G$, Oldervoll $L$. The effect of exercise on fatigue and physical functioning in breast cancer patients during and after treatment and at 6 months followup: a meta-analysis. Breast. 2017;33:166-77.

47. Harmon KG, Drezner JA, Wilson MG, Sharma S. Incidence of sudden cardiac death in athletes: a state-of-the-art review. Heart. 2014;100(16):1227-34.

48. Tiziano FD, Palmieri $V$, Genuardi $M$, Zeppilli $P$. The role of genetic testing in the identification of young athletes with inherited primitive cardiac disorders at risk of exercise sudden death. Frontiers in Cardiovascular Medicine. 2016;3

49. Priori SG, Blomström-Lundqvist C, Mazzanti A, Blom N, Borggrefe M, Camm J, Elliott PM, Fitzsimons D, Hatala R, Hindricks G: 2015 ESC Guidelines for the management of patients with ventricular arrhythmias and the prevention of sudden cardiac death. Europace 2015:euv319.

50. Cañadas V, Vilacosta I, Bruna I, Fuster V. Marfan syndrome. Part 1: pathophysiology and diagnosis. Nature reviews Cardiology. 2010;7(5):256.

51. von Kodolitsch Y, De Backer J, Schüler H, Bannas P, Behzadi C, Bernhardt AM, Hillebrand M, Fuisting B, Sheikhzadeh S, Rybczynski M. Perspectives on the revised Ghent criteria for the diagnosis of Marfan syndrome. Appl Clin Genet. 2015;8:137.

52. Ramachandra CJ, Mehta A, Guo KWQ, Wong P, Le Tan J, Shim W. Molecular pathogenesis of Marfan syndrome. Int J Cardiol. 2015;187:585-91.

53. Eynon N, Hanson ED, Lucia A, Houweling PJ, Garton F, North KN, Bishop DJ. Genes for elite power and sprint performance: ACTN3 leads the way. Sports Med. 2013;43(9):803-17.

54. McCarthy MI, MacArthur DG. Human disease genomics: from variants to biology. Genome Biol. 2017;18(1):20.

55. Rankinen T, Fuku N, Wolfarth B, Wang G, Sarzynski MA, Alexeev DG, Ahmetov II, Boulay MR, Cieszczyk P, Eynon N. No evidence of a common DNA variant profile specific to world class endurance athletes. PLoS One. 2016;11(1):e0147330.

56. Willems SM, Wright DJ, Day FR, Trajanoska K, Joshi PK, Morris JA, Matteini AM, Garton FC, Grarup N, Oskolkov N. Large-scale GWAS identifies multiple loci for hand grip strength providing biological insights into muscular fitness. Nat Commun. 2017:8

57. Voisin S, Guilherme JPF, Yan X, Pushkarev VP, Cieszczyk P, Massidda M, Calò CM, Dyatlov DA, Kolupaev VA, Pushkareva YE. ACVR1B rs2854464 is 
associated with sprint/power athletic status in a large cohort of Europeans but not Brazilians. PLoS One. 2016;11(6):e0156316.

58. Miyamoto-Mikami E, Murakami H, Tsuchie H, Takahashi H, Ohiwa N, Miyachi M, Kawahara T, Fuku N. Lack of association between genotype score and sprint/power performance in the Japanese population. J Sci Med Sport. 2017;20(1):98-103.

59. Yang R, Shen X, Wang Y, Voisin S, Cai G, Fu Y, Xu W, Eynon N, Bishop DJ, Yan X. ACTN3 R577X gene variant is associated with muscle-related phenotypes in elite Chinese Sprint/power athletes. The Journal of Strength \& Conditioning Research. 2017;31(4):1107-15.

60. He T, Zhong P-S, Cui Y. A set-based association test identifies sex-specific gene sets associated with type 2 diabetes. Front Genet. 2014;5

61. Schaafsma SM, Gagnidze K, Reyes A, Norstedt N, Månsson K, Francis K, Pfaff DW. Sex-specific gene-environment interactions underlying ASD-like behaviors. Proc Natl Acad Sci. 2017:201619312.

62. Webborn N, Williams A, McNamee M, Bouchard C, Pitsiladis Y, Ahmetov I, Ashley E, Byrne N, Camporesi S, Collins M. Direct-to-consumer genetic testing for predicting sports performance and talent identification: consensus statement. Br J Sports Med. 2015;49(23):1486-91.

63. Kutz G: Direct-to-consumer genetic tests: misleading test results are further complicated by deceptive marketing and other questionable practices: congressional testimony: DIANE publishing; 2010.

64. Covolo L, Rubinelli S, Ceretti E, Gelatti U. Internet-based direct-to-consumer genetic testing: a systematic review. J Med Internet Res. 2015;17(12)

65. Saukko P. State of play in direct-to-consumer genetic testing for lifestylerelated diseases: market, marketing content, user experiences and regulation. Proceedings of the Nutrition Society. 2013;72(01):53-60.

66. Borry P, Van Hellemondt RE, Sprumont D, Jales CFD, Rial-Sebbag E, Spranger TM, Curren L, Kaye J, Nys H, Howard H. Legislation on direct-to-consumer genetic testing in seven European countries. Eur J Hum Genet. 2012;20(7): 715-21

67. Annas GJ, Elias S. 23andMe and the FDA. N Engl J Med. 2014;370(11):985-8.

68. Edwards KT, Huang CJ. Bridging the consumer-medical divide: how to regulate direct-to-consumer genetic testing. Hastings Cent Rep. 2014;44(3): $17-9$

69. Vlahovich N, Fricker PA, Brown MA, Hughes D. Ethics of genetic testing and research in sport: a position statement from the Australian Institute of Sport. Br J Sports Med. 2017:51(1):5-11.

70. Green ED, Guyer MS, Institute NHGR. Charting a course for genomic medicine from base pairs to bedside. Nature. 2011;470(7333):204-13.

71. Delaney SK, Hultner ML, Jacob HJ, Ledbetter DH, McCarthy JJ, Ball M, Beckman KB, Belmont JW, Bloss CS, Christman MF. Toward clinical genomics in everyday medicine: perspectives and recommendations. Expert Rev Mol Diagn. 2016;16(5):521-32.

72. Gibson WT. Genetic association studies for complex traits: relevance for the sports medicine practitioner. Br J Sports Med. 2017;43:314-316.

73. Guth LM, Roth SM. Genetic influence on athletic performance. Curr Opin Pediatr. 2013;25(6):653.

74. Polcz S, Lewis A: CRISPR-Cas9 and the non-germline non-controversy. Journal of Law and the Biosciences 2016:Isw016.

75. World Anti-Doping Code. In. Edited by World Anti-Doping Agency; 2015.

76. Hayden EC. The $\$ 1000$ genome. Nature. 2014;507(7492):294.

77. Barton MK. Health behaviors not significantly changed by direct-toconsumer genetic testing. CA Cancer J Clin. 2017;

78. Gray SW, Gollust SE, Carere DA, Chen CA, Cronin A, Kalia SS, Rana HQ, MTR IV, Wang C, Roberts JS, et al. personal genomic testing for cancer risk: results from the impact of personal genomics study. J Clin Oncol. 2017; 35(6):636-44.

79. Verhagen EA, van Stralen MM, Van Mechelen W. Behaviour, the key factor for sports injury prevention. Sports Med. 2010;40(11):899-906.

80. Bollen JC, Dean SG, Siegert RJ, Howe TE, Goodwin VA. A systematic review of measures of self-reported adherence to unsupervised home-based rehabilitation exercise programmes, and their psychometric properties. BMJ Open. 2014;4(6):e005044

81. Picorelli AMA, Pereira LSM, Pereira DS, Felício D, Sherrington C. Adherence to exercise programs for older people is influenced by program characteristics and personal factors: a systematic review. J Phys. 2014;60(3): 151-6.

82. Lauersen JB, Bertelsen DM, Andersen LB. The effectiveness of exercise interventions to prevent sports injuries: a systematic review and metaanalysis of randomised controlled trials. Br J Sports Med. 2014;48(11):871-7.
83. McCall A, Dupont G, Ekstrand J: Injury prevention strategies, coach compliance and player adherence of 33 of the UEFA Elite Club Injury Study teams: a survey of teams' head medical officers. Br J Sports Med 2016: BJSPORTS-2015-095259.

84. Collard D, Singh A, Verhagen E. The behavioural approach. Sports injury research. 2010;16(1):157.

85. Eldredge LKB, Markham CM, Kok G, Ruiter RA, Parcel GS: Planning health promotion programs: an intervention mapping approach: John Wiley \& Sons; 2016.

\section{Submit your next manuscript to BioMed Central and we will help you at every step:}

- We accept pre-submission inquiries

- Our selector tool helps you to find the most relevant journal

- We provide round the clock customer support

- Convenient online submission

- Thorough peer review

- Inclusion in PubMed and all major indexing services

- Maximum visibility for your research

Submit your manuscript at www.biomedcentral.com/submit
C Biomed Central 